\title{
Serum vitamin D3 levels in pregnant women with preeclampsia at third trimester of pregnancy
}

\author{
Anas H. Sadek ${ }^{1,2}$, Rayah S. Baban ${ }^{1}$, May F. Al-Habib ${ }^{3}$ and Enas A. Khazaali ${ }^{4}$ \\ ${ }^{1}$ Department of Chemistry and Biochemistry, College of Medicine, Al-Nahrain University, Baghdad, Iraq \\ ${ }^{2}$ Faculty of Dentistry, Dijlah University College, Baghdad, Iraq \\ ${ }^{3}$ Department of Anatomy, Histology and Embryology, College of Medicine, Al-Nahrain University, Baghdad, Iraq \\ ${ }^{4}$ Department of Obstetrics and Gynecology, College of Medicine, Al-Nahrain University, Baghdad, Iraq
}

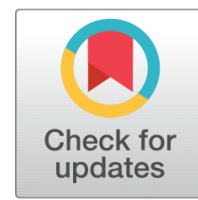

Received 16-04-2021

Revised 24-07-2021

Accepted 25-07-2021

Published 26-07-2021

\section{Corresponding Author}

Anas H. Sadek

anas.hashem@duc.edu.iq

Faculty of Dentistry, Dijlah University College, Baghdad, Iraq

DOI https://doi.org/10.47419/

bjbabs.v2i03.42

Pages: 160-166

Distributed under

the terms of the Creative

Commons

Attribution-NonCommercial 4.0 International (CC-BY-NC 4.0), which permits use for any non-commercial purpose, distribution, and reproduction in any medium, provided that the original work is properly cited.

Copyright: (c) 2021 Anas H. Sadek, Rayah S. Baban, May F. Al-Habib, Enas A. Khazaali

\section{OPEN ACCESS}

\section{ABSTRACT}

Background: Preeclampsia (PE) is a pregnancy-specific condition, characterized by high blood pressure and proteinuria after 20 weeks of gestation. One of the hypotheses concerning the etiology of PE is vitamin D3 deficiency during pregnancy. Vitamin D3 is especially important during pregnancy as low maternal vitamin D3 stores may contribute to problems like low birth weight as well as an increased risk of maternal comorbidities.

Objectives: To evaluate serum vitamin D3 levels and how they can be affected by the severity of $\mathrm{PE}$ at the third trimester of pregnancy.

Methods: This case-control study included a total of 71 pregnant women at the third trimester of pregnancy (41 with PE and 30 without PE as controls). Vitamin D3 serum level was measured by enzyme-linked immune-sorbent assay (ELISA).

Results: The study's findings showed no significant difference in serum vitamin D3 level $(p>0.05)$ between controls $(14.41 \pm 1.41 \mathrm{ng} / \mathrm{ml})$ and PE patients $(14.32 \pm 1.00$ $\mathrm{ng} / \mathrm{ml}$ ). As well, subgroup analysis revealed non-considerable changes between mild PE cases $(15.92 \pm 1.73 \mathrm{ng} / \mathrm{ml})$ and severe ones $(13.07 \pm 1.09 \mathrm{ng} / \mathrm{ml})$.

Conclusions: PE and its severity may have no significant effect on serum vitamin D3 levels of pregnant women at the third trimester of pregnancy.

Keywords early-onset preeclampsia, late-onset preeclampsia, pregnancy, third trimester, vitamin D

\section{INTRODUCTION}

Preeclampsia (PE), a disorder that complicates $2-8 \%$ of pregnancies, is a leading cause of maternal and fetal morbidity and mortality. ${ }^{1}$ Its diagnosis is based mainly on elevated blood pressure (BP: systolic BP of $140 \mathrm{mmHg}$, or diastolic BP of $90 \mathrm{mmHg}$ ), and proteinuria that occur after week 20 of gestation in women who were not previously diagnosed with hypertension or other manifestations such as renal impairment, thrombocytopenia, hepatic 
dysfunction, pulmonary edema, or cerebral/visual disturbances. ${ }^{2}$ The clinical features of this disorder involve newly-onset hypertension and proteinuria but the specific definition for PE varies according to different guidelines and between countries. ${ }^{3} \mathrm{PE}$ is capable of being separated into two major kinds, the early and the late onset PE. This classification is depending either on the onset period or the identification of the syndrome. ${ }^{3}$ The late onset PE comprises the majority ( $>80 \%)$ of preeclamptic cases. In the early onset type, the clinical symptoms appear prior to week 33 of gestation, while regarding late onset kind they happen following week 34 . Early-onset PE is associated with an increased risk of short and long-term maternal complications and perinatal mortality and morbidity. ${ }^{1,4}$ The risk factors include previous PE, chronic renal disease, chronic hypertension, diabetes mellitus, systemic lupus erythematosus or antiphospholipid syndrome, first pregnancy, maternal age $>35$ years, body mass index $>35 \mathrm{~kg} / \mathrm{m}^{2}$, inter-pregnancy interval $>10$ years, family history of PE. ${ }^{5}$

The prominent role of vitamin D3, a hormone, in bone homeostasis was firstly reported in the early decades of the $20^{\text {th }}$ century the discovery that rickets might be prevented and treated by sun exposure. It led to isolation and identification of vitamin D2 (ergocalciferol) and vitamin D3 (cholecalciferol), then the knowledge about vitamin D role as immunomodulatory, anti-inflammatory, anti-fibrotic, and antioxidant was grew. ${ }^{6,7}$ Adequate levels of vitamin D3 are essential for bone health, immune function, proliferation and differentiation of cells, inflammation, insulin secretion and action, and vascular health. Its deficiency is common worldwide and its metabolism is markedly altered during pregnancy for reasons not fully understood. ${ }^{8}$ Vitamin D3 (also called bioactive vitamin D, 1,25-dihydroxyvitamin D3, 1,25-(OH $)_{2} \mathrm{D} 3$, calcitriol, or 1,25-dihydroxycholecalciferol) is a pluripotent hormone and important modulator of both innate and adaptive immunity, and serum total 25hydroxyvitamin D (25(OH)D) is commonly used to assess individual vitamin D3 status. ${ }^{9}$ Estimates of levels of vitamin D3 in the serum of pregnant females has aided researchers in evaluating the frequency of deficiency of vitamin D3, and it has also helped in understanding both maternal and fetal outcomes that are associated with such deficiencies. Fetus development during pregnancy is fully reliant on the mother's stores of vitamin D3, and so, the condition of the mother's vitamin D3 levels is crucial for fetal development. Throughout pregnancy, the fetus maintains increments of $1,25-(\mathrm{OH})_{2} \mathrm{D} 3$ more than that required and this amount increases to the point of birth. ${ }^{10}$ Limited reports are there to evaluate the vitamin D3 status in pregnant women at the third trimester of pregnancy, particularly, in those with PE. Thus, the current communication aims to evaluate vitamin D3 levels in pregnant women with $\mathrm{PE}$ at the third trimester of pregnancy.

\section{MATERIALS AND METHODS}

\section{Study design and subjects}

This case-control study was designed and laboratory work was conducted at the Department of Chemistry and Biochemistry, College of Medicine, Al-Nahrain University from 
June 2019 to March 2020. The participants in the current study were 71 pregnant women at the third trimester of pregnancy (41 with $\mathrm{PE}$ and 30 without $\mathrm{PE}$ as controls) of those who registered at Al-Imamain Al-Kadhimain Medical City. All women who included in this research were subject, by their physician, to physical examination, blood pressure measurement, and laboratory investigations.

\section{Inclusion and exclusion criteria Inclusion criteria}

All pregnant women included in this study were in the third trimester. Pregnant women aged 18 - 45 years, within the gestational age of $\geq 22$ - 40 weeks, singleton pregnant women. Patients with arterial hypertension defined by systolic BP $\geq 140 \mathrm{mmHg}$ or diastolic BP $\geq 90 \mathrm{mmHg}$, proteinuria greater than $0.3 \mathrm{~g} / 24 \mathrm{~h}$ or $3 \mathrm{~g} / \mathrm{L}$, proteinuria/creatinine ratio $>30$ $\mathrm{g} / \mathrm{mmol}$, and generalized edema with or without thrombocytopenia $<150000 / \mathrm{mm}^{3}$ were included in this study. Healthy pregnant women met the following criteria; pregnancy with normal blood pressure $(<140 / 90 \mathrm{mmHg})$, absence of proteinuria.

\section{Exclusion criteria}

Chronic hypertension, renal and liver diseases, diabetes mellitus, smokers, fetal structural abnormalities, multiple pregnancy, intrauterine fetal growth restriction from other causes, heart failure, inflammatory disorders, elderly pregnants, infectious disease, endocrine disease, HELLP syndrome and collagen vascular disease

\section{Biochemical analyses}

Five milliliters of venous blood had been withdrawn from each pregnant woman by the use of disposable syringes in the sitting situation. Then, it was discharged gradually in disposable test tubes without anticoagulant (gel tube), and left to clotting for 10 to $15 \mathrm{~min}$ at $37^{\circ} \mathrm{C}$. After the samples were clotted, they were centrifuged at $1000_{x} g$ for $10-15 \mathrm{~min}$ and serum samples were separated and stored in epindorff tubes at $-80^{\circ} \mathrm{C}$ until analysis of vitamin D3 (vit. D3). At the day of analysis, the samples were thawed and analysed for vitamin D3 using enzyme linked immunosorbent assay (ELISA) kit (Calbiotech, El Cajon, California, U.S.A.) according the manufacturer's instructions.

\section{Statistical analysis}


Data was expressed as mean \pm standard error mean $(\mathrm{m} \pm \mathrm{SEM})$, and statistically evaluated using SPSS software v. 26 (IBM, USA). Based on the normality test result, the data was analysed using the parametric test $t$-test. A $p$ value $\leq 0.05$ were considered statistically significant.

\section{RESULTS}

The age and vitamin D3 levels of the preeclamptic pregnant women and healthy control subjects are presented in table 1 and table 2 . Statistical analysis, using student's t-test, showed no significant differences ( $p=0.957)$ between serum vitamin D3 of control women $(14.41 \pm 1.41$ $\mathrm{ng} / \mathrm{ml})$ and that of patients groups $(14.32 \pm 1.00 \mathrm{ng} / \mathrm{ml}, p=0.957)$. Also, non-considerable $(\mathrm{p}=0.155)$ change in vitamin $\mathrm{D}$ concentration was noted between mild $(15.92 \pm 1.73 \mathrm{ng} / \mathrm{ml})$ and severe $(13.07 \pm 1.09 \mathrm{ng} / \mathrm{ml}) \mathrm{PE}$ patients.

\begin{tabular}{|c|c|c|c|}
\hline & Control $(n=30)$ & $\operatorname{PE}(n=41)$ & $P$ \\
\hline Age (years) & $29.7 \pm 1.37$ & $29.05 \pm 0.97$ & 0.697 \\
\hline Vitamin D3 (ng/ml) & $14.41 \pm 1.41$ & $14.32 \pm 1.00$ & 0.957 \\
\hline
\end{tabular}

$\boldsymbol{P E}$, preeclampsia

\begin{tabular}{|c|c|c|c|}
\hline & Mild PE (n=18) & Severe PE $(n=23)$ & $P$ \\
\hline Age (years) & $27.44 \pm 1.63$ & $30.30 \pm 1.14$ & 0.146 \\
\hline Vitamin D3 (ng/ml) & $15.92 \pm 1.73$ & $13.07 \pm 1.09$ & 0.155 \\
\hline
\end{tabular}

PE, preeclampsia

\section{DISCUSSION}

The results of the recent study showed that there was no significant difference $(p>0.05)$ in means of maternal age of control group when compared with patients groups (mild and severe PE) (Table 1), also there was no significant difference ( $p>0.05$ ) between mild and severe PE groups (Table 2). These findings agreed with those of Nasser et al. (2020), ${ }^{11}$ Sharabi-Nov et al. (2021) who showed no significant differences in the mean of age for PE and control normotensive individuals. ${ }^{11,12}$ In the current study, the levels of serum vitamin D3 showed no significant differences between pre-eclamptic pregnant women and normal controls (Table 1). All study groups showed vitamin D3 deficiency and this may be due to low exposure to sunlight, inadequate dietary vitamin D3 intake and seasonal variation. 
Also, this study consistent with previous study which found that there was no significant difference in serum 25(OH)D levels between mild, severe PE and control groups. Also, there was no association between $25(\mathrm{OH}) \mathrm{D}$ deficiency and preeclampsia severity in the study. ${ }^{13}$

\section{CONCLUSION}

The results of this study suggest that PE may have no effects on vitamin D levels in pregnant women in the third trimester of pregnancy. Also, a non-considerable change in vitamin D concentrations was noted between mild and severe PE patients.

\section{ACKNOWLEDEGMENTS}

The authors would like to thank the technical staff of Al-Imamain Al-Kadhimain Medical City, and the staff of the Chemistry and Biochemistry Department, College of Medicine, Al-Nahrain University where the practical part of this work has been carried out.

\section{DECLARATIONS}

\section{Authors' contributions}

Conceptualization: RSB, AHS, MFA, EAK. Data curation: AHS, RSB, MFA, EAK. Formal analysis: RSB, AHS, MFA, EAK. Funding acquisition: N/A. Investigation: RSB, AHS, MFA, EAK. Methodology: RSB, AHS, MFA, EAK. Project administration: AHS. Resources: RSB, AHS, MFA, EAK. Software: RSB, AHS, MFA, EAK. Supervision: RSB, MFA. Validation: RSB, AHS, MFA, EAK. Visualization: RSB, AHS, MFA, EAK. Writing-original draft, review and editing: RSB, AHS, MFA, EAK. All authors have read, reviewed and approved the final version of this paper before publication.

\section{Conflict of interest}

There are no conflicts of interest to declare.

\section{Ethical approvals}

This research was approved by the Institutional Review Board (IRB) at the College of Medicine, Al-Nahrain University. And before participation, all women were given an idea about the study and their agreement was taken.

\section{Data availability}

The data that support the findings of this study are available from the corresponding author, upon reasonable request.

\section{Funding resources}

This research was self-funding and no external funding was received. 


\section{REFERENCES}

1. Serra B, Mendoza M, Scazzocchio E, Meler E, Nolla M, Sabrià E, et al. A new model for screening for early-onset preeclampsia. Am J Obstet Gynecol. 2020;222(6):608.e1-608.e18. Available from: 10.1016/j.ajog.2020.01.020.

2. Nasser NA, Baban RS, Al-Habib MF, Jameel RAA. The association between urinary placental protein 13 and soluble fms- like tyrosine kinase- 1 in preeclamptic women in the third trimester of pregnancy. Baghdad J Biochem Appl Biol Sci. 2020;1(01):4651. Available from: 10.47419/bjbabs.v1i01.31.

3. von Hellens H, Keski-Nisula L, Sahlman H. Increased risk of preeclampsia after use of paracetamol during pregnancy - causal or coincidence? BMC Pregnancy Childbirth. 2021;21(1):24-24. Available from: 10.1186/s12884-020-03490-x.

4. Nasser NA, Baban RS, Al-Habib MF, Jameel R. Correlation between Serum \& Urinary Placental Protein (Pp13) in Pre-eclamptic Women at their Third Trimester. Indian J Forensic Med Toxicol. 2020;

5. Bohiltea R, Cirstoiu M, Turcan N, Stoian A, Zugravu CA, Munteanu O, et al. Inherited thrombophilia is significantly associated with severe preeclampsia. Experimental and Therapeutic Medicine. 2021;21(3):261-261. Available from: 10.3892/etm. 2021.9691.

6. Bellan M, Andreoli L, Mele C, Sainaghi PP, Rigamonti C, Piantoni S, et al. Pathophysiological Role and Therapeutic Implications of Vitamin D in Autoimmunity: Focus on Chronic Autoimmune Diseases. Nutrients. 2020;12(3):789-789. Available from: 10.3390/nu12030789.

7. Ebadi M, Montano-Loza AJ. Perspective: improving vitamin D status in the management of COVID-19. European Journal of Clinical Nutrition. 2020;74(6):856-859. Available from: 10.1038/s41430-020-0661-0.

8. Kelly CB, Wagner CL, Shary JR, Leyva MJ, Yu JY, Jenkins AJ, et al. Vitamin D Metabolites and Binding Protein Predict Preeclampsia in Women with Type 1 Diabetes. Nutrients. 2020;12(7):2048-2048. Available from: 10.3390/nu12072048.

9. Radujkovic A, Hippchen T, Tiwari-Heckler S, Dreher S, Boxberger M, Merle U. Vitamin D Deficiency and Outcome of COVID-19 Patients. Nutrients. 2020;12(9):27572757. Available from: 10.3390/nu12092757.

10. Albakaa AAH, Naser AM, Saleim AR. Determination of Pregnant women Knowledge toward Risk Factors of Vitamin D Deficiency and Measuring Level During Pregnancy in Al- Nasiriyah City. Ann Trop Med Public Health. 2020;23(13). Available from: 10.36295/asro.2020.231333.

11. Nasser NA, Baban RS, Al-Habib MFM, Jameel RAA. Serum placental growth factor (PLGF) and soluble fms-like tyrosine kinase- 1(sFLT-1) in preeclamptic women at their third trimester of pregnancy. Baghdad J Biochem Appl Biol Sci. 2020;1(01):3945. Available from: 10.47419/bjbabs.v1i01.30.

12. Sharabi-Nov A, Sršen TP, Kumer K, Vodušek VF, Fabjan T, Tul N, et al. Maternal Serum Inhibin-A Augments the Value of Maternal Serum PlGF and of sFlt1/PlGF Ratio in the Prediction of Preeclampsia and/or FGR Near Delivery-A 
Secondary Analysis. Reprod Med. 2021;2(1):35-49. Available from: 10.3390/ reprodmed2010005.

13. Sima H, Amir NE, Mohammad Z, Elham HK, Zahra D, Fatemeh M, et al. The Relationship of Vitamin D and Calcium level with Preeclampsia Severity: A Case- control Study. Int J Pediatr. 2017;5(6):42-42. 